\title{
El poder, el mito y la dominación en El otoño del patriarca
}

\section{Power, myth and domination in Autunm of the Patriarch}

\author{
Alba Nidia Morin Flores \\ Universidad Nacional Autónoma de México-MÉXICO \\ nidiamorin30@gmail.com
}

\section{Resumen}

El presente trabajo estudia la concepción del poder en El otoño del patriarca, para tal efecto se analizan las principales posturas teóricas sobre dicho tópico, particularmente sobre el poder como dominación. Aunado a lo anterior, se identifican los mecanismos generadores de obediencia, tanto coactivos como voluntarios presentes en la novela, especialmente la construcción del mito del dictador como forma de dominación del pueblo y paralelamente se analiza su desmitificación. La configuración mitológica del patriarca en la obra revela la historia común de los pueblos latinoamericanos dominados por las figuras dictatoriales en aras del "orden” frente al caos y la inestabilidad sufrida en los periodos post independentistas.

Palabras clave: Poder, dominación, dictadura, mito, derecho y literatura.

\begin{abstract}
The essay studies the conception of power in The Autumn of the Patriarch, for this purpose the main theoretical positions on this topic are analyzed, particularly on power as domination. In addition to the above, the mechanisms that generate obedience, both coercive and voluntary, present in the novel are identified, especially the construction of the dictator's myth as a form of people domination, and its demystification is analyzed in parallel. The mythological configuration of the patriarch in the work reveals the common history of the Latin American villages dominated by dictatorial figures for the sake of "order" versus chaos and the instability suffered in the post-independence periods.
\end{abstract}

Key words: Power, domination, dictature, myth, law and literature.

Recibido: 20 de noviembre de 2020 - Aceptado: 25 de enero de 2021

Autoctonía. Revista de Ciencias Sociales e Historia Vol. V, Nº 1, Enero-Junio 2021, 48-68 ISSN 0719-8213

DOI: http://dx.doi.org/10.23854/autoc.v5i1.191 


\section{Introducción}

El tema del poder ha sido abordado de manera constante dentro de las disciplinas sociales y humanas. La filosofía, la teoría política, la sociología y el derecho desde diversas perspectivas y vertientes se han acercado a dicho fenómeno para comprender los problemas planteados en el entorno social. La literatura, como forma de conocimiento de la realidad no ha escapado al tratamiento del tema del poder aportando una concepción cifrada a través de la narración que permite entender desde diferentes perspectivas su lógica y sus procesos atendiendo al locus de enunciación y a la realidad contextual.

Dentro de la literatura latinoamericana El otoño del patriarca (1975) escrita por Gabriel García Márquez sobresale por el tratamiento del tema del poder, además porque junto a novelas como Yo el Supremo (1974) de Augusto Roa Bastos y El recurso del método (1975) de Alejo Carpentier forma parte de la "trilogía" de obras que consolida el subgénero literario denominado la novela del dictador, la cual, aunque presenta problemáticas de definición, constituye una forma de crítica social en respuesta al contexto dictatorial sufrido en América Latina.

La riqueza contenida en la novela de García Márquez no solo se comprueba a través de la gran cantidad de artículos, ensayos y trabajos escritos sobre las manifestaciones culturales, míticas e históricas que presenta la obra, sino además porque permite trazar una concepción del poder a partir de los fenómenos históricos en los cuales se inspira.
El patriarca caracterizado por sus dones "sobre humanos", la longevidad, su "resurgir" cíclico durante los más de ciento cincuenta años en los que gobernó la isla del Caribe se configura como un mito a partir del cual se puede advertir la dominación dictatorial en la historia latinoamericana.

\section{I.- Aproximación al concepto de poder}

En la historia de las sociedades, la reflexión y debate en torno al poder ha sido una constante. El tema ha ocupado un lugar de vital importancia entre filósofos y científicos sociales. Desde Aristóteles (1988) quien afirmó que "Mandar y obedecer no solo son cosas necesarias, sino también convenientes, y ya desde el nacimiento algunos están destinados a obedecer y otros a mandar. Y hay muchas formas de mandar." Se han desarrollado una serie de teorías tratado de entender la naturaleza, el origen y la tipología del poder (Aristóteles, 1988: 56).

Así, en diferentes épocas, diversos pensadores han realizado aportaciones a la comprensión del fenómeno. Sin embargo, el acercamiento a su estudio enfrenta grandes problemáticas especialmente porque hasta el día de hoy, no hay un consenso en la forma de concebirlo, analizarlo y conceptualizarlo, es decir, no hay un corpus teórico uniforme. Los estudios al respecto divergen en cuanto a sus cualidades esenciales, orígenes y ejercicio.

De esta manera, existe una diversidad de posturas y conceptualizaciones discrepantes, pues para autores como Max Weber (1964), el poder está estrechamente vinculado a la idea de violencia, 
para otros como Hannah Arendt (2006) éste se asocia con el consenso y para otros como Michel Foucault (2002) el poder se vincula a la producción de realidades y fracasa cuando se manifiesta a través de la violencia y la coerción 1 . A pesar de ello, al ser un fenómeno inherente a las sociedades sigue constituyendo una cuestión central en la reflexión política, filosófica, sociológica y jurídica; su abordaje teórico resulta de suma actualidad para las disciplinas sociales y humanas al constituir un inagotable foco de reflexión.

Ahora bien, una de las principales y más influyentes posturas teóricas sobre el poder es la de Max Weber (1979) para quien este concepto se encuentra íntimamente vinculado con otros como Estado, política y el ejercicio de la violencia. El autor considera que sociológicamente el Estado debía ser definido en función a sus medios y no a sus fines, pues éste no ha poseído un solo fin específico o una actividad esencialmente dedicada al uso exclusivo de dicha asociación. Partiendo de este supuesto, atendiendo a sus medios, la violencia física ha sido el medio específico del Estado. De esta manera, además del elemento humano (comunidad humana) y el elemento territorial (elemento distintivo) la exclusividad de la violencia física es un rasgo definitorio del Estado (Weber, 1979: 83).

En esa tesitura, la política y el poder encuentran relación con los conceptos previos ya que la política es la dirección o influencia sobre el Estado y representa la participación, distribución del poder o de los intereses que sobre él existan. Por tanto, las decisiones o cuestiones políticas refieren al poder, entendido por el autor como un concepto amorfo y definido como "la probabilidad de imponer la propia voluntad, dentro de una relación social, aun contra toda resistencia y cualquiera que sea el fundamento de esa probabilidad" (Weber, 1964: 43). Este concepto de poder refiere a la imposición de la voluntad y consecución de una acción a pesar de toda oposición, es decir, el poder es concebido a partir de la imposición, la resistencia y la acción.

El concepto de poder en Weber (1964) no representa una preocupación central en su teoría social, en comparación con el concepto de dominación que desarrolla ampliamente. Para él, la dominación se relaciona con la obediencia, el mandato y la subordinación ya que es "la probabilidad de encontrar obediencia a un mandato determinado contenido entre personas dadas" (Weber, 1964: 43). La dominación de unos hombres sobre otros se encuentra sostenido por la violencia legítima, es decir, la dominación siempre es legítima pues quienes se someten a ella la reconocen como tal. Dicha legitimidad encuentra su justificación a través de la costumbre (legitimidad tradicional), por el carisma de quien la ejerce (legitimidad carismática) o por la norma (legitimidad basada en la legalidad) (Weber 1979: 87).

Frente al concepto weberiano de poder unido a la violencia, a la resistencia y al conflicto, se hallan concepciones causales o relacionales que entienden a éste como la capacidad de lograr que un agente haga lo que por sí mismo no habría hecho, en este sentido se halla la postura de Robert Dahl (1957) quien sostiene que A tiene poder sobre B en la medida en que puede conseguir con éxito que $B$ 
haga algo que de otra manera no haría. (Dahl, 1957: 203)

El concepto que Dahl propone gira en torno al ejercicio del poder, pues se centra en el resultado de las acciones e influencias de A sobre B, es decir, sugiere la verificabilidad de las decisiones tomadas de forma empírica. Para el autor, esta concepción surge de la relación entre personas y posibilita la clasificación del poder de los miembros del Senado en temas como la política exterior, es decir, es aplicable para entender la adopción de decisiones.

Además de los conceptos previos, se advierten posicionamientos críticos que conciben al poder como la imposición de intereses en las prácticas de clase, como el de Nicos Puolantzas (2007) quien con la pretensión de colmar el vacío en el pensamiento marxista formuló un concepto, para ello comienza por distinguir entre niveles estructurales de una formación social y niveles de lucha de clases sociales, es decir, entre estructuras y relaciones sociales. Para el autor, el poder se constituye dentro de las relaciones sociales o prácticas de clase, pues éstas son relaciones de poder. Por tanto, el poder no se encuentra en la estructura, sino en las relaciones entre clases.

Tomando en cuenta lo anterior, define al poder como "la capacidad de una clase social para realizar sus intereses objetivos específicos." (Poulantzas, 2007: 124). Con esta definición, el autor pone en el centro de análisis las clases sociales y los intereses (de clase), pues para él, el poder no puede ser concebido en términos de estructuras sino en términos de una clase social sobre otras. De manera que, no puede hablarse del poder del
Estado porque el poder no radica en la estructura sino en las relaciones sociales, ello indica que el poder permea de las estructuras a las relaciones sociales o prácticas llevadas a cabo entre las clases sociales y sus luchas.

El conflicto como rasgo característico del poder, se vincula con lo dicho por Weber (1964), aunque ambos parten de posturas ideológicas diversas -Weber (historicista) y Poulantzas (2007) (marxista)-y aunque, como hemos mencionado, conciben particularidades propias de concepción ambos refieren al conflicto. Además, relacionan al poder con la imposición de la voluntad, de unos sobre otros, ya sea individuos, grupos, instituciones o clases sociales, de manera que se consigue la realización de los propios intereses dañando los intereses de los otros.

Frente a estas posturas, se identifican otras maneras de conceptualización del poder, cuyas referencias se alejan de los términos antes aludidos como imposición, violencia o coacción, es decir, parten de supuestos teóricos que vinculan a éste con el consenso ${ }^{2}$ o los fines colectivos ${ }^{3}$, entre ellos se encuentra el análisis del poder de Hannah Arendt (2006).

Para esta filósofa alemana el estado actual de la ciencia política es triste por la inexistencia de una precisión conceptual e identificación de términos como poder, autoridad, fuerza o violencia. Dicha situación es de suma importancia porque ello no solo implica el desconocimiento o imprecisión del significado lingüístico, sino porque se inadvierten realidades a las que corresponden y además, se pasan por alto cuestiones políticas trascendentales 
como la reducción de los asuntos públicos al tema del dominio. (Arendt, 2006: 60).

En su reflexión sobre el poder, se remonta a las civilizaciones griega y romana donde, el imperio de la ley y el poder del pueblo (potestas in populo) eran conceptos unidos. De acuerdo con ello, para la filósofa, el poder es una capacidad humana enteramente referenciada a la propiedad de un grupo mientras permanezca unido, es decir, no existe el poder como propiedad individual. En ese sentido hace una diferencia entre el poder y la potencia, el primero lo usa para referirse a la capacidad del grupo (concertadamente), en cambio el segundo lo usa para referirse a la metáfora de un hombre poderoso (Arendt, 2006: 60).

En esta tesitura, el poder se origina en el pueblo como característica inherente al grupo. Por tanto, las instituciones son materializaciones del poder que encuentran legitimidad en el consenso y no en la violencia, pues ésta es solo un medio para conseguir un fin y no constituye un rasgo esencial del poder. Por tanto, la concepción del poder de Arendt se aleja de las formas concepciones relacionadas con el ejercicio de la violencia, la amenaza y la coacción, contraviniendo a teóricos como Weber (1964) quienes consideran a la violencia como una manifestación del poder.

En este sentido, autores como Steven Lukes (2007) elaboran críticas a las concepciones del poder como las de Max Weber (1964) o Robert Dahl (1957) por considerarlas restrictivas y unidimensionales, pues inobservan manifestaciones del poder relacionadas con el control de los pensamientos y deseos (Lukes, 2007: 19). En el mismo sentido se encuentra el pensamiento de Michel Foucault (1999) y Byung-Chul Han (2017) para quien comprender al poder en términos restrictivos de control y coacción es un error.

Michel Foucault (1999), uno de los más grandes pensadores del poder, considera que es necesario entender a éste más allá de la represión, la censura y la prohibición, es decir, lograr una ruptura con su concepción meramente jurídica permite entender su funcionamiento real (Foucault, 1999: 239). En esta tesitura, su concepto confronta y rompe con las formulaciones clásicas del poder, sostenidas en la amenaza, coerción y violencia y con aquellas formulaciones que conciben al poder como propiedad de determinadas clases sociales. $Y$ aunque no proporciona una definición formal de lo que debe entenderse por poder sí hace un análisis profundo y puntual sobre el funcionamiento de las relaciones de poder y los mecanismos a través de los cuales el poder constituye a los individuos.

De esta manera, desde la óptica foucaultiana, el poder deja de vincularse únicamente a los efectos coercitivos "Hay que cesar de describir siempre los efectos del poder en términos negativos: "excluye", "reprime", "rechaza", "censura", "abstrae", "disimula", "oculta". De hecho, el poder produce; produce realidad” (Foucault, 2002: 192). La función primordial de los poderes no es la prohibición, sino la producción de realidades. Por tanto, el poder incrementa su eficiencia cuando no se muestra a través de la coerción o la amenaza.

En consecuencia, los efectos del poder se producen en los individuos atravesándolos y conformándolos a través de microprácticas instituidas como 
prácticas cotidianas en las sociedades modernas. Desde esta postura teórica, el ejercicio del poder no se presenta de forma vertical ${ }^{4}$ a través de la represión o el mandato, sino que éste se esconde detrás de mecanismos más sutiles y claros que la sociedad y cultura sugieren. Así, para Foucault el poder es un concepto mucho más amplio que no refiere únicamente a las concepciones restrictivas de orden y coacción, la posibilidad de pensarlo más allá de esos límites permite el descubrimiento de los mecanismos menos evidentes que lo estructuran y posibilitan su develamiento.

Es importante señalar que, para el filósofo francés, hay una distinción entre las relaciones de dominación y las relaciones de poder, pues las primeras son relaciones que no permiten a los participantes la modificación de las estrategias usadas sino que estas se encuentran bloqueadas. Las refiere como relaciones fijas, perpetuamente disimétricas y en donde el espacio de libertad es muy limitado (Foucault, 1994: 259). En cambio, en las relaciones de poder se ejercen sobre la libertad y existe el espacio de resistencia.

Por otra parte, en la postura teórica de Byung-Chul Han (2017) es un error entender al poder a través de la coacción o como posibilidad de imposición frente a cualquier resistencia ya que éste opera de forma sigilosa sin mostrarse abiertamente (Byung-Chul, 2017:19). El poder del poder radica en la generación de acciones sin que necesariamente exista una orden. En este sentido, desde su análisis lógico el poder no necesita un mandato $\mathrm{u}$ orden expresa, es decir, tiene éxito sin ser revelado porque "el poder del poder" radica en que no se manifiesta explícitamente y aun así, puede motivar las acciones.

Ahora bien, las diversas concepciones del poder que se han enunciado hasta el momento conciben a éste dando predominancia a ciertos elementos como la violencia, la imposición de la voluntad, el consenso, la lucha de clases, o bien, se enfocan en descubrir los mecanismos a través de los cuales actúa. Debido a ello, reina el caos teórico.

Para Lukes (2007), la problemática en el estudio del poder es consecuencia de la confusión entre el concepto de éste como capacidad, el vehículo de dicha capacidad y su ejercicio. Para el autor, el poder tiene una definición genérica referida a la capacidad de los agentes sociales (individuales o colectivos) que incluye tanto los poderes activos, es decir, aquellos ejercidos por la voluntad del agente como los pasivos, esto es, aquellos que los agentes poseen con independencia de su voluntad (Lukes, 2007: 79).

Esta forma de comprender al poder, contraria gran parte de las concepciones previas, pues la mayor parte de los teóricos vinculan a este con el poder de unos sobre otros. Ante tal circunstancia, el británico sostiene que el poder asimétrico es un subconcepto del poder genérico (Lukes, 2007: 83). De manera que, apoyado en la distinción efectuada por Baruch Spinoza distingue entre la potentia y la potestas; la primera, entendida como el poder de las cosas en la naturaleza; la segunda, concebida como el ser bajo el fuero de otro. (Lukes, 2007: 82). 
Así, el concepto de poder genérico aludido por el autor es referido al poder como potentia, en tanto que el poder de uno sobre otros es un subconcepto del primero, esto es, el poder como potestas. Éste último, es definido como “...la capacidad de tener a otro u otros en poder de uno, limitando sus posibilidades de decisión, con lo que se asegura la obediencia." (Lukes, 2007: p.83). Dentro de los resultados conseguidos por éste se encuentra la dominación. El ejercicio de la dominación produce obediencia, la cual puede ser producto de la coerción o ser voluntaria.

El poder como dominación es el resultado de la capacidad de limitar las posibilidades de decisión a partir de la coacción o de forma voluntaria, impidiendo a los dominados vivir bajo sus propios juicios y provocando una afectación en los intereses de aquellos a quienes se les ha restringido o limitado su capacidad de decisión. (Lukes, 2007: 100).

Ahora bien, de lo expuesto anteriormente, se advierte la recurrencia histórica que el abordaje del tema del poder ha suscitado entre los miembros de la comunidad científica y aunque no hay uniformidad en el corpus teórico, sus concepciones proporcionan guías de análisis al acercamiento del fenómeno, el cual en la actualidad no han dejado de cobrar importancia y encuentra ecos en otras manifestaciones humanas como el arte, especialmente en la literatura, cuestión que será abordada en la siguiente sección.

\section{II.- La literatura y el poder. La novela del dictador}

El arte es una manifestación propia del ser humano y constituye una forma de expresión imprescindible para el hombre. La importancia de éste radica, para algunos, en que "intenta penetrar en la realidad de la vida humana, en la realidad de las relaciones entre el hombre y su mundo por la vía de expresión de sentimientos estéticos" (Recasens, 1998: 639). De manera que, la obra artística descifra la realidad desde diferentes locus de enunciación permitiendo nuevas formas de vislumbrarla.

De entre las artes, la literatura por medio de la palabra interpreta la realidad y contribuye a la comprensión del mundo. Así, a través de los siglos se advierte cómo grandes obras literarias como Las mil y una noches, La Orestiada, Edipo, La divina comedia, Hamlet, Crimen y Castigo, Madame Bovary, Ulises, Don Quijote de la Mancha, 1984, El proceso, Cien años de soledad entre muchas otras, se erigen como formas de vislumbrar, cuestionar y entender la realidad.

Ahora bien, si el poder tiene que interesar a todos porque en toda sociedad se ejerce un mando (Juovenal, 2008: 36) es natural que la temática haya sido abordada no solo por la comunidad científica sino también por otras comunidades como la de escritores desde cuyas plumas se ha advertido el fenómeno del poder. Así, los literatos por un lado y el poder por el otro, encuentran un vínculo íntimo en la obra literaria.

La literatura entonces constituye un campo de reflexión sobre el poder que, desde diversos ángulos y aproximaciones, cuestionan su ejercicio, su legitimidad, sus peligros, sus abusos y arbitrariedades haciendo visible sus problemáticas y limitaciones. De esta manera, a través de sus distintos géneros 
y usos del lenguaje la obra literaria realiza una crítica social aguda a la forma en que el poder se manifiesta y de quienes lo detentan.

Dentro de los géneros literarios destaca particularmente la novela en el tratamiento de la temática del poder. Y es que, desde el siglo XIX ésta ha sido analizada como un discurso que posee dos dimensiones, la forma (estilo) y el contenido (significado) o bien, un estilo y un contenido ideológico. De manera que, dentro de las formas actuales de acercarse a su a nálisis se encuentran aquellas que encuentran en ella el reflejo de la lucha ideológica. (Beltrán, 2019: 16).

De esta forma, desde diversas latitudes obras como El nombre de la rosa, Memorias de Adriano, Calígula, Macbeth, 1984, El maestro y Margarita forman un corpus de novelas que centran en él su foco de reflexión. Sin embargo, sobresale en América Latina un subgénero literario nombrado por la crítica como la novela del dictador el cual constituye una forma de crítica social y visión política característica de la narrativa latinoamericana vertida por parte de los escritores durante gran parte del siglo XX.

La novela del dictador comprende ciertas obras literarias que comparten la temática dictatorial como elemento central de la narración, la cual encuentra un vínculo con la realidad política y social de la región caracterizada por el abuso del poder en los regímenes autoritarios de la que fueron víctimas las sociedades de esta parte planeta, pues se advierte históricamente cómo la región latinoamericana a partir de las guerras de Independencia ha sido proclive a la aparición de dictaduras debido a la inestabilidad y las profundas agitaciones sociales por el choque constante de intereses. Todo esto provocó la aparición de caudillos y hombres interesados en el mando, lo cual terminó por la imposición de las dictaduras y la falta de límites en el ejercicio del poder.

En esta tesitura, de acuerdo a algunos críticos literarios, surge un corpus de novelas cuyo eje transversal constituye el poder y especialmente la figura del dictador. $Y$ es que, América Latina ha sido silenciada por diversos regímenes dictatoriales, por tanto, las cuestiones políticas y sociales han sido tratadas por los escritores quienes se convirtieron en las pocas voces escuchadas (Fuentes, 1972; Goloboff, 1991).

Ahora bien, aunque a partir de los años setenta, la mayoría de los críticos aceptan la existencia de dicho subgénero literario, no existe una comunión de pareceres respecto a sus elementos distintivos. Para algunos autores el tratamiento de la temática dictatorial es la característica que permite agrupar al corpus de novelas y abordarlo diferenciadamente (Bellini, s.a; Pacheco, 1987; Sandoval, 1989). Sin embargo, para otros, la figura del dictador como objeto narrativo diferenciable es el criterio que permite diferenciar la narrativa de ciertas obras literarias y agruparlas bajo dicha denominación (Rama, 1976; Milliani, 1981; Subercaseaux, 1980).

En el primer supuesto se ubica Juan José Amate (1981), para quien a partir de Facundo o Civilización y Barbarie (1845), El Matadero (1838) y Amalia (1851), se funda el subgénero, pues son las primeras obras en abordar la temática dictatorial (Amate, 
1981: 102). Por su parte, Adriana Sandoval (1989) considera solo a Amalia (1851) como la obra fundacional, pues la temática dictatorial enmarca el desarrollo de la narración (Sandoval, 1989: 27).

Para otros, en cambio, el dictador como objeto narrativo puede producir dos tipos de novela; la primera, en donde existe una discursividad que se expande hasta formar una atmósfera dictatorial, pero el dictador no es el centro de la narración; la segunda, en la que el dictador constituye el objeto diferenciado y aparece como el eje fundamental de la trama (Milliani, 1981: 208). En este sentido, para Bernardo Subercaseaux, el subgénero literario se delimita al diferenciar entre la novela del dictador (el dictador constituye un objeto narrativo) y la novela con dictador (dictadores individualizados). (Subercaseaux, 1980: 335)

En esa tesitura, Ángel Rama (1976) sostiene que el cambio de narrativa de la simple temática dictatorial a la interiorización en la conciencia del dictador es la característica fundamental del subgénero, considera la publicación de las novelas El recurso del método (1974), El otoño del patriarca (1975) y Yo el supremo (1975) como fundacionales porque reflexionan sobre el poder absoluto que se ha ejercido unipersonalmente en la región desde la interioridad del dictador. En ellas se advierte la profundidad en el abordaje de la conciencia del dictador, misma que genera la concreción de un nuevo subgénero. (Rama, 1976:26).

De lo dicho anteriormente se advierte la inexistencia, dentro de la crítica literaria, de criterios que permitan identificar y delimitar con certeza los elementos necesarios y las singularidades que distingan las obras pertenecientes al subgénero literario denominado "novela del dictador" y permitan distinguirlas de otras manifestaciones artísticas.

En este sentido, tal vez se tendría que plantear, como Rodríguez Freire (2015) señala, la necesidad de deconstruir el archivo de la llamada "narrativa latinoamericana", pues el pretender establecer modelos o cánones fijos silencia la diversidad y pluralidad de obras que no se ajustan a ellos. Quizá en el caso de la novela del dictador, la crítica literaria y la industria editorial ha colocado dicho rótulo a un conjunto de novelas por suponer la existencia de una narrativa latinoamericana esencialmente política, adjudicado la temática dictatorial a ésta como si perteneciera a su esencia identitaria.

A pesar de lo anterior, algunos autores identifican rasgos que singularizan a la novela del dictador y encuentran en la omnisciencia, ubicuidad y distanciamiento del narrador, la configuración del mundo como un cielo al revés, en donde al dictador se le confieren cualidades divinas y es omnipresente, la estructura del personaje configurada de tal forma que todas las líneas que sigue la obra empiezan y terminan en él, la invención del país en donde se desarrolla la trama y la existencia de personajes antagónicos al dictador y trasfondo social los elementos característicos de la narrativa (Subercaseaux, 1980: 326).

Otros, en cambio, consideran que la estructuración a partir de la figura del dictador, sea ésta central o no, el espacio y tiempo indeterminados, la existencia de un lenguaje autorreferencial que 
lo acerca a la reflexión crítica y la manifestación de la dialéctica entre el dictador y el pueblo son rasgos singulares del subgénero (Ferrer, 2016: 300)

Como se advierte, el binomio literatura y poder encuentra un punto de unión en la llamada novela del dictador, reflejo de la realidad dictatorial vivenciada por los países latinoamericanos, y aunque no haya una comunión de pareceres sobre el corpus que lo conforma, la crítica literaria considera a El otoño del patriarca como obra cúspide a esta narrativa.

\section{III. - Sobre El otoño del patriarca: el autor y su obra}

Gabriel García Márquez (1927-2014) es considerado uno de los escritores latinoamericanos más sobresalientes del siglo XX. Es nombrado por algunos autores como el escritor más grande que América Latina ha producido en los últimos siglos, un verdadero revolucionario del lenguaje $\mathrm{y}$ forjador de una identidad cultural colectiva (Martínez et. al., 2014: 18).

El colombiano tuvo una amplia producción literaria dentro de la que destacan obras como La hojarasca (1955) con la cual se introdujo en el mundo de las letras, El amor en los tiempos del cólera (1985), Crónica de una muerte anunciada (1981), El coronel no tiene quien le escriba (1961) o Memorias de mis putas tristes (2004), última novela del escritor. Recibió el premio nobel de literatura en 1982 y aunque la mayor parte de su obra ha tenido amplio reconocimiento internacional, Cien años de soledad (1967) ha sido su trabajo más destacado.
Después del éxito que dicha novela generó entre los lectores y los críticos literarios escribir El otoño del patriarca (1975), significó, para el autor, un desafío estilístico y un reto profesional, pues distanciarse de la narrativa presente en su obra más reconocida fue una ardua tarea que implicó más de diez años de trabajo; sin embargo, la historia del dictador latinoamericano constituyó su contribución más significativa "Literariamente hablando, el trabajo más importante, el que puede salvarme del olvido, es El otoño del patriarca...Es el libro que desde siempre quise escribir, y además aquel en que he llevado más lejos mis confesiones personales" (Mendoza, 2015: 74).

Así, García Márquez escribe una obra que sobresale por su naturaleza poética y complejidad estructural, cuya riqueza narrativa es de tales dimensiones que permiten una gran diversidad de temáticas de estudio más allá del evidente tema de la dictadura.

Dentro de ese marco, críticos como José Miguel Oviedo (1981) profundizan sobre las mujeres y el matriarcado desde la imagen de Bendición Alvarado y Úrsula Iguarán; Fernando Moreno Turner (2016) propone una lectura sobre los estereotipos culturales del continente a partir de la relación que entabla el patriarca con su madre; Julio Ortega (1978) aborda los elementos de la cultura popular y lo mitológico en la novela; Ángel Rama (1986) se centran en la temática de la soledad advirtiendo en el dictador una bestia solitaria; Seymour Menton (1981) identifica en la obra la evolución histórica del continente y Francisca Noguerol (1992) estudian al personaje central 
como arquetipo o molde narrativo producido en América Latina.

Como se advierte, la riqueza narrativa de la novela posibilita su estudio y análisis desde diferentes ángulos, los cuales incluyen temáticas mayormente abordadas como la tiranía, la soledad, el poder y otras que abordan tópicos relacionados con la cultura popular, la historia, lo mítico o la vejez. Sin embargo, de entre las posibles formas de abordaje destaca la temática del poder como obsesión recurrente en toda la producción literaria del autor, pues de acuerdo al colombiano, el poder ha sido una temática constante en la narrativa latinoamericana desde sus orígenes y su obra no ha sido la excepción, dicho tema le provocaba una gran fascinación y, como él mismo admitió, "no era una fascinación secreta”.

En este orden de ideas y tomando en cuenta que toda obra artística responde a un contexto de creación que signa la producción estética, pues así como el artista escribe desde un locus de enunciación, la obra no puede escindirse de la realidad contextual se advierte el contexto dictatorial latinoamericano como el campo de cultivo que da lugar a la historia del dictador de la novela. En este sentido, durante el tiempo en el cual García Márquez escribe $\mathrm{El}$ otoño del patriarca, las dictaduras militares se encontraban presentes en la mayor parte de los países del continente como aquellas impuestas en Bolivia por Hugo Banzer de 1971 a 1978, en Nicaragua por los Somoza de 1934 hasta 1979, en Haití por Francois Duvalier de 1957 a 1971 o en República Dominicana la dictadura de Rafael Leónidas Trujillo de 1930 a 1961.
En esta tesitura, de acuerdo al escritor colombiano, aunque con el personaje de Zacarías quiso simbolizar a todos los dictadores de América Latina y particularmente del Caribe, su fascinación por la personalidad de Juan Vicente Gómez provocó que el patriarca tuviera más rasgos idealizados de él que de otros dictadores. (Mendoza, 2015: 102). A pesar de ello, en la obra se identifican comportamientos que aluden a gran parte de los dictadores en la historia del continente.

Por otra parte, como se advirtió previamente, si bien, no se desconoce la problemática planteada anteriormente sobre la inexistencia de criterios certeros que permitan advertir características de la novela del dictador El otoño del patriarca es considerada por gran parte de la crítica como una de las obras cúspide del subgénero caracterizada por los elementos propuestos por Subercaseaux (1980) y Carlos Ferrer (2016).

En esa tesitura, la novela se estructura a propósito de la figura del dictador, quien funge como personaje central, el cual se construyó a partir de las figuras históricas dictatoriales presentes en América Latina y cuya imagen es la de un "militar" anciano, analfabeta, "con el pecho blindado de falsas victorias", mantenido en el poder por los gobiernos extranjeros, hundido en una profunda soledad y a quien se le atribuían cualidades divinas “...pues siempre parecía que se desdoblaba, que lo vieron jugando dominó a las siete de la noche y al mismo tiempo lo habían visto prendiendo fuego a las bostas de vaca“" (García Márquez, 2015; 15).

El patriarca en la obra es quien ejerce el poder, lo obtuvo en el tiempo en que éste "era un sábalo 
fugitivo que nadaba sin dios ni ley en un palacio de vecindad, perseguido por la cáfila voraz de los últimos caudillos de la guerra federal" (García Márquez, 2015; 58). Así, en el tiempo de profunda inestabilidad los caudillos habían ayudado al dictador a tomar el poder a través del derrocamiento de Lautaro Muñoz.

En principio, Zacarías pudo representar desde la concepción weberiana a un líder carismático, un conductor de hombres (Weber, 1979: 87) "un hombre mesiánico que en los orígenes de su régimen aparecía en los pueblos a la hora menos pensada...no dejaba sin esclarecer un solo detalle en cuanto conversaba con los hombres y mujeres que había convocado" (García Márquez, 2015; 91) "no había una contrariedad de la vida cotidiana que no tuviera para él tanta importancia como el más grave de los asuntos de estado y creía de buen corazón que era posible repartir la felicidad y sobornar a la muerte con artimañas de soldado" (García, Márquez 2015; 93). Sin embargo, conforme transcurre la obra se advierte su gobierno como imposición de potencias extranjeras y la obediencia del pueblo derivada de todo, menos de la entrega.

Por otra parte, cada uno de los capítulos de la obra son circulares y comienzan refiriéndose a la muerte del patriarca, la primera sección señala "...y allí lo vimos a él, con el uniforme de lienzo sin insignias, las polainas, la espuela de oro en el talón izquierdo...y estaba tirado en el suelo bocaabajo, con el brazo derecho doblado bajo la cabeza" (García Márquez, 2015; 10) y en la tercera parte comienza "Así lo encontraron en las vísperas del otoño, cuando el cadáver era en realidad el de Patricio Aragonés..." (García Márquez, 2015; 90).

Siguiendo con los elementos propuestos por Ferrer (2016), se advierte en la obra, su imprecisión espacial y temporal, pues no se precisa la isla del Caribe en la cual ésta se desarrolla y coexisten temporalmente acontecimientos históricos pertenecientes a diversas épocas, desde la llegada de Colón hasta el apoyo de las dictaduras por parte de potencias extranjeras. Por otra parte, también se reconoce la dialéctica con el pueblo “...repetían de memoria abajo la opresión, gritaban, muera el tirano, y hasta los centinelas de la casa presidencial leían en voz alta por los corredores la unión de todos sin distinción de clases contra el despotismo de siglos, la reconciliación patriótica contra la corrupción y la arrogancia de los militares..." (García Márquez, 2015; 28).

De lo dicho anteriormente, se advierte cómo El otoño del patriarca como parte de la novela del dictador, permite la construcción del andamiaje entre la literatura, la historia, la teoría política y la filosofía. Precisamente a partir de estos últimos tópicos se abordarán los siguientes apartados.

\section{El poder en la novela}

La crítica literaria ha estudiado en El otoño del patriarca una multiplicidad de temas tan variados que van desde los estudios culturales hasta los procesos históricos de la región. Sin embargo, el poder ha adquirido especial relevancia porque surgió de la reflexión que el autor realizó de su fascinación por las figuras dictatoriales. 
Y es que desde el primer acercamiento a la obra destacan tres elementos relacionados directamente con el poder; el primero, consiste en la contextualización del poder a un régimen dictatorial; el segundo, radica en la desmesura temporal de la dictadura; el tercero, estriba en la mitificación del personaje y al mismo tiempo su desmitificación o humanización. Estos elementos forman parte indispensable en la concepción del mismo.

En primer lugar, es evidente el ambiente dictatorial que describe el autor, desde las primeas líneas se advierte la relación asimétrica instaurada entre el patriarca y los gobernados, caracterizada por la violencia, la coacción, la tortura y la reducción de las libertades fundamentales. Esta es la referencia más visible del poder en la obra, ya que en variados pasajes, se advierte:

los hizo colgar de una viga horizontal como loros atados de pies y manos y con la cabeza hacia abajo durante muchas horas...hizo que echaran a uno en el foso del patio y los otros lo vieron descuartizado y devorado por los caimanes...escogió a uno del grupo principal y lo hizo desollar vivo en presencia de todos y todos vieron el pellejo tierno y amarillo como una placenta recién parida...y entonces confesaron lo que él quería que les habían pagado cuatrocientos pesos de oro para que arrastraran el cadáver...(García Márquez, 2015; 41).

La abolición de garantías, la inexistencia de derechos humanos, la desaparición forzada, la tortura, el encarcelamiento, los asesinatos ejercidos sobre el pueblo por parte del patriarca como mecanismos coercitivos generalmente empleados en la reducción de libertades llevada a cabo por los dictadores y en este caso por parte de Zacarías encuentran, en principio una relación directa con el poder.

Yes que, lainexistencia delibertades fundamentales y la concentración del poder son rasgos presentes en las dictaduras pues el poder de los gobernantes sobre los gobernados es ilimitado y las garantías fundamentales no existen (Rouquié, 1981; 1) Estos rasgos son identificables en la narración, pues a través de la limitación y abolición de las libertades mínimas el patriarca imponía su voluntad.

Aunado a lo anterior se identifica la desmesura temporal como rasgo característico del poder dictatorial descrito en la novela, pues no se sabe con exactitud durante cuántos años el patriarca gobernó al pueblo, solo a manera de indicio se señalan más de 150 años. Este rasgo se suma al tercer elemento característico del poder en la novela: el mito del patriarca.

La mitificación y posterior desmitificación del dictador en la obra juegan un papel central en la concepción del poder, pues el autor pareciera que con ello devela sus caras ocultas, pues por una parte, sobresalen la serie de relatos míticos que se construyen alrededor del patriarca y la desmesura en todos los aspectos de su vida, desde la longevidad hasta los poderes sobre humanos atribuidos al dictador "asediado por una muchedumbre de leprosos, ciegos y paralíticos que suplicaban de sus manos la sal de la salud...que lo proclamaban corregidor de los terremotos, los eclipses, los años bisiestos y otros errores de Dios" 
(García Márquez, 2015; 14) y por otra parte resalta la desmitificación o humanización del dictador como un hombre, viejo, terriblemente solo.

Ahora bien, aunque la concepción del poder en la novela contempla la descripción de la violencia, la fuerza y la coacción, la obra no hace un especial énfasis en los sufrimientos causados por el dictador al pueblo, ni en las diversas formas de tortura o en las atrocidades cometidas durante su régimen, en cambio, resalta como figura central en la concepción del poder al mito del dictador y la desmesura temporal de su régimen. De esta manera, el poder se aleja de las concepciones reduccionistas, nombradas por algunos autores como formas unidimensionales de entenderlo que identifican al poder con la imposición de la voluntad (Lukes, 2007: 19) y descubre mecanismos menos evidentes en los que se manifiesta el poder.

Para algunos autores, esta relación asimétrica entre el dictador y el pueblo caracterizada por la inexistencia de libertades, formaría parte de la relaciones de dominación y no de las relaciones de poder precisamente por la disimetría y por la limitación en el espacio de libertad (Foucault, 1994: 259). En el mismo sentido, partiendo de la distinción entre el poder y la dominación realizada por Weber (1989) algunos pasajes de la obra sugieren que, al comienzo de la relación entre el dictador y el pueblo, especialmente con la guardia presidencial, se evidencia la dominación cuya legitimidad encontraría justificación en el carisma “...la guardia presidencial que cumplió con mucho gusto y a mucha honra mi general su orden feroz que nadie escapara con vida del conciliábulo de la traición.” (García Márquez, 2015: 37).
Sin embargo, tras un proceso interpretativo, tomando en cuenta la desmesura temporal, los elementos coercitivos y la construcción del mito del dictador se considera que la novela ofrece una concepción del poder vinculada al poder como dominación, es decir, un subconcepto del poder genérico caracterizado por la asimetría, la limitación en la toma de decisiones y la obediencia, la cual puede ser coercitiva o voluntaria (Lukes, 2007: 32).

Así, junto a las formas coercitivas mediante las cuales se asegura de la obediencia en la obra, se hallan mecanismos menos evidentes, pero igualmente eficaces para garantizar la dominación del pueblo en donde se ubica la configuración del mito del patriarca, el cual incidía en la mente de los gobernados a través del miedo y la veneración que producía la figura del patriarca.

De manera que, se identifica la concepción del poder en la obra como un poder de uno sobre otros, en donde los intereses de los dominados bajo el régimen fueron afectados en todo momento, los parámetros de libertad eran inexistentes y en donde la obediencia se generaba, por una parte, a través de la coerción y, por la otra, a través de la construcción del mito del dictador.

\section{El mito del patriarca}

De acuerdo con Joseph Campbell, los mitos han estado siempre presentes en la historia de los grupos humanos a lo largo del tiempo, aun cuando las historias han variado en su representación, constituyen una constante. Éstos son generados espontáneamente en la psique del hombre, las 
artes, la ciencia y la religión emanan de ellos (Campbell, 1959, p.10).

Los mitos son experiencias de la vida que la animan, es decir, son realidades vivas, tratan sobre los grandes problemas humanos y permiten advertir sus profundas necesidades, no son imágenes o símbolos ajenos a la vida, son realidades experimentadas. Son definidos como "metáforas de lo que yace debajo del mundo visible" (Campbell, 1991, p. 21). Entre los mitos, el del héroe cobra relevancia, pues el ciclo cosmogónico sigue a través de los héroes más que de los dioses y a través de ellos se realiza el destino del mundo (Campbell, 1959: 177).

En esa tesitura, en El otoño del patriarca el mito del héroe tirano es representado por el dictador latinoamericano como símbolo de "autoridad" y "orden" a partir del cual se ejerce el poder y la dominación al pueblo que cree en la divinidad de su figura. El patriarca es una especie de deidad, cuyo mito forma parte de los mecanismos que aseguran la dominación en la isla del caribe. El personaje se configura a partir del cúmulo de voces presentes en la obra. A lo largo de la novela, no se sabe con exactitud cuál de las historias contadas responden a la realidad, pues existe una mezcla de relatos cíclicos contradictorios que conforman la figura del dictador. Dichas historias son transmitidas de generación en generación y lo representan como una especie de semi dios inmune al trascurso del tiempo.

Aunque "nadie lo ha visto", los relatos del pueblo le confieren una serie de características míticas, desde su edad fluctuante entre los 100 y los 235 años hasta las circunstancias extraordinarias de su nacimiento, ya que había nacido del vientre de Bendición Alvarado quien "lo había concebido sin concurso de varón” (García Márquez, 2015: 53), además de sus poderes extraordinarios intrínsecos:

de modo con que bastaba que él señalara con el dedo a los árboles que debían dar fruto y a losanimalesque debían crecery a los hombres que debían prosperar, y había ordenado que quietaran la lluvia de donde estorbaba las cosechas y la pusieran en tierra de sequía, y así había sido, señor, yo lo he visto, pues su leyenda había empezado mucho antes de que él mismo se creyera dueño de todo su poder (García Márquez, 2015: 94).

En Zacarías, sobresale además la potencia sexual como otra peculiaridad frecuentemente encontrada en los personajes míticos. Este rasgo se destaca en toda la obra, pues el patriarca tuvo casi "siete mil hijos todos sietemesinos" (García Márquez, 2015: 52). De esta manera, el patriarca representaba para el pueblo una especie de deidad y objeto de veneración, cuyo vasto poder se equiparaba al de los dioses:

lo referían como un patriarca de tamaño descomunal que nunca salía de su casa porque no cabía por las puertas, que amaba a los niños y a las golondrinas, que conocía el lenguaje de algunos animales, que tenía la virtud de anticiparse a los designios de la naturaleza, que adivinaba el pensamiento con solo mirar a los ojos y conocía el secreto de una sal de virtud para sanar las lacras de 
los leprosos y hacer caminar a los paralíticos (García Márquez, 2015: 52).

Los poderes atribuidos a Zacarías eran extraordinarios, no solo tenía el poder de gobernar a los hombres, sino a la misma naturaleza, podía cambiar el cauce de los ríos, curar a los enfermos e incluso determinar la hora y el día en que los astros debían de aparecer, es decir, poseía un poder ilimitado y desmesurado al grado de regalar cometas a sus enamoradas: "Hoy le traigo el regalo más grande del universo, un prodigio del cielo que va a pasar hoy a las once cero seis, para que tú lo veas, reina, solo para que tú lo veas, y era el cometa" (García Márquez, 2015: 85).

Como figura mítica, el patriarca está destinado a gobernar eternamente, pues a su muerte "el silencio y las tinieblas se volverían a establecer en el universo porque aquél había de ser el término de la creación.” (García Márquez, 2015: 129).

Así, en gran parte de la novela, García Márquez describe la imagen mitificada del patriarca. Sin embargo, paralelamente aparece la mundanidad del mismo, con ello el escritor colombiano rompe con el mito del dictador al develar su miseria. Zacarías en realidad es un militar cuyas victorias de guerras eran inventadas por sus aduladores, procreado por "uno de tantos fugitivos de vereda... lo habían engendrado de pie y sin quitarse el sombrero" (García Márquez, 2015: 135). Un anciano débil, lleno de miedo "el temblaba ante la idea de encontrarse solo entre la gente de sus sueños" (García Márquez, 2015: 66) embriagado de poder cuyo costo es la más inmensa soledad.
De esta manera, el mito del patriarca constituye una de las formas mediante las cuales se asegura la obediencia y con ello la dominación sobre el pueblo por conformar una creencia transmitida por generaciones en donde el dictador aparece como una especie de deidad cuya imposibilidad de muerte junto a sus poderes sobre humanos y su destino como "eterno gobernante" influían en la población para aceptar la dictadura. La serie de relatos tergiversados aunada a la ignorancia, la miseria, la violencia y el sometimiento juegan en la obra un papel central en la dominación.

\section{El mito y la experiencia latinoamericana}

El mito del dictador aparece en El otoño del patriarca como realidad común de los pueblos latinoamericanos, durante gran parte del siglo XIX y XX el dictador constituyó una de las figuras centrales en la historia de América Latina, personajes como Alfredo Stroessner, Jean Pierre Boyer, Juan Manuel Rosas, Augusto Pinochet, Jorge Rafael Videla o Rafael Leónidas Trujillo, resuenan en la memoria colectiva de la región. "Algunos se llaman a sí mismos "presidentes", de acuerdo con el lenguaje republicano, otros se llaman oficialmente "dictadores", de acuerdo con el más puro lenguaje aristotélico, otros, "jefes supremos", "directores supremos", "presidentes vitalicios" o "dictadores vitalicios". Uno que otro es investido como "Emperador" (Labastida, 1980: 224).

La obra analizada advierte la construcción del mito en torno a las figuras dictatoriales vivenciadas en América Latina, el cultivo de éste alrededor del dictador permite entender el ejercicio del poder y la dominación, así como el apoyo a la dictadura 
como forma necesaria del orden. Y es que el mito posee una función sociológica, la cual fundamenta y da validez a un orden social (Campbell, 1991: 65).

De esta manera, advirtiendo los orígenes de las dictaduras en América Latina, la figura del dictador fue producto de las necesidades de dirección y organización del pueblo frente al caos e inestabilidad que reinaba al finalizar las luchas independentistas. Por tanto, surgen figuras como los caudillos populares y los grandes propietarios quienes se disputaban el mando y que en la obra quedan identificados "a cambio de sus servicios de armas...y se habían repartido el país...con el argumento inapelable de que este es el federalismo" (García Márquez, 2015: 58).

Siguiendo a Pablo González Casanova (1980) ${ }^{5}$ frente al profundo desorden e inestabilidad en el ámbito económico, político (eran frecuentes los cuartelazos, intervenciones militares y golpes de Estado) y la instrumentalización de las ideas sobre la democracia y soberanía popular, por ello comienzan a emerger dichas figuras patriarcales en aras de un supuesto "orden".

Con el transcurso del tiempo y con ayuda de la hegemonía de los Estados Unidos sobre América Latina se impusieron regímenes cuyos dictadores nativos (Centroamérica y el Caribe) sostuvieron las dictaduras en atención a la "seguridad nacional", situación que aparece claramente en la novela "usted no es el presidente de nadie...lo sentaron los ingleses y lo sostuvieron los gringos" (García, 2015: 31).
El discurso de la "seguridad nacional" fue el estandarte mediante el cual las dictaduras justificaron las medidas tomadas como la matanza de los intelectuales y políticos no convenientes por ser una amenaza. Discursivamente se abogó por ideas democráticas en beneficio de los derechos humanos, al mismo tiempo se propugnó por campañas de satanización hacia los opositores y se proclamaron nuevos instrumentos constitucionales restrictivos de la democracia.

De esta forma, la generación del mito de los "hombres providenciales" sobre los cuales se tejió un entramado de "salvadores del pueblo" y "héroes" permaneció a lo largo de décadas en la región latinoamericana. La inmortalidad del patriarca en la obra parece recordar el regreso de esas personalidades en nuestra historia común. Estos personajes se percibieron a sí mismos como figuras indispensables de representación histórica, grandes personalidades ególatras cuya creencia se encontraba fundamentada en su "divinidad" y legitimidad.

La obra muestra como la "bolita del poder" detentada por los dictadores latinoamericanos parece evadirlos de la realidad incitándolos a pensarse como seres "elegidos" legitimados para atropellar, torturar, asesinar, desaparecer y cometer actos de barbarie en contra de todos aquellos que se atraviesan en su camino por el mandato de salvación de un pueblo que llega a creer en ellos como figuras de orden.

La historia de América Latina muestra a los dictadores como grandes megalómanos singularizados 
por la desmesura y las excentricidades en el ejercicio del poder:

...la independencia del dominio español no nos puso a salvo de la demencia. El general Antonio López de Santa Anna, tres veces dictador de México, hizo enterrar con funerales magníficos la pierna derecha que había perdido en la llamada Guerra de los pasteles. El General García Moreno, gobernó el Ecuador durante dieciséis años como un monarca absoluto y su cadáver fue velado con su uniforme de gala y su coraza de condecoraciones sentado en la silla presidencial... (García Márquez, 1982: s.p)

De esta manera, El otoño del patriarca recuerda el mito construido a partir de la figura del dictador (mecanismo de dominación) y lo contrapone a la realidad de los hombres de poder en la historia de América Latina al romper con la magia y hacer evidente la más cruda mundanidad de los dictadores como hombres ordinarios, de baja condición social, marginados, excluidos, tomados como marionetas de gobiernos extranjeros con la pesada "carga" del poder cuya vida termina en la soledad y el olvido, lejos de ser los dioses que alguna vez anhelaron:

...él se quedó sin saberlo para siempre con el dulce silbido de su potra de muerto viejo tronchado de raíz por el trancazo de la muerte, volando entre el rumor oscuro de las últimas hojas heladas de su otoño hacia la patria de las tinieblas de la verdad del olvido, agarrado de miedo a los trapos de hilachas podridas del balandrán de la muerte y ajeno a los clamores de las muchedumbres frenéticas que se echaban a las calles cantando los himnos de júbilo de la noticia jubilosa de su muerte y ajeno para siempre jamás a las músicas de liberación y los cohetes de gozo y las campanas de gloria que anunciaron al mundo la buena nueva de que el tiempo incontable de la eternidad había por fin terminado (García Márquez: 2015: 270).

\section{Conclusiones}

Desde las sociedades antiguas, la reflexión sobre el poder ha ocupado un lugar de vital importancia. A lo largo del tiempo diversos autores han teorizado sobre su concepción, orígenes y manifestación sin lograr llegar a un corpus teórico uniforme. La literatura desde una óptica distinta también ha advertido el fenómeno del poder. Así, los escritores por un lado y el poder por el otro, encuentran especialmente en la novela un punto de conexión.

Dicha unión cobra particular importancia dentro de la narrativa latinoamericana por dar origen a la novela del dictador, la cual reflexiona en torno al poder a propósito de las figuras dictatoriales y aunque en la actualidad no han sido determinados los elementos necesarios que definen al subgénero, gran parte de los críticos advierte en El otoño del patriarca una pieza cúspide. En ella, Gabriel García Márquez junto a las formas coercitivas de generar obediencia (tortura, asesinatos, desapariciones) revela en el mito del dictador una forma voluntaria de la dominación, lo cual se acerca a la concepción teórica denominada el poder como dominación. 
La configuración del mito del patriarca en la novela evoca la historia común de los pueblos latinoamericanos y recuerda la aparición de caudillos y figuras dictatoriales como respuesta a las necesidades de dirección y organización frente al caos e inestabilidad producto de las luchas independentistas. De esta forma, El otoño del patriarca representa una manera de observar la realidad común latinoamericana a partir del mito de los hombres de "poder" y paralelamente muestra lo ordinario, marginal y mundano de los dictadores latinoamericanos.

\section{Referencias citadas}

Arendt, H. (2006): Sobre la violencia, Madrid: Alianza Editorial.

Aristóteles (1988): Política. Madrid: Gredos.

Bellini, G. (2008): "El tema de la dictadura en la narrativa del mundo hispánico (Siglo XX)", Disponible en Biblioteca virtual Miguel de Cervantes: http://www. cervantesvirtual.com/obra/el-tema-de-la-dictaduraen-la-narrativa-del-mundo-hispnico---siglo-xx-0/

Beltrán, L. (2019): “La novela, género literario”, Letras, 66, pp. 13-45.

Byung-Chul, H. (2017): Sobre el poder, Madrid, Herder.

Campbell, J. (1959): El héroe de las mil caras. Psicoanálisis del mito, México, FCE.

Campbell, J. (1991): El poder del mito, Barcelona, Emce Editores.
Dahl, R. A. (1957): “The concept of power”, Behavioral Science, 2 (3), pp. 201-215.

Ferrer, C. (2016): Poética de la novela del dictador hispanoamericano. Origen, evolución y agotamiento de un subgénero novelístico, Tesis doctoral no publicada, Universidad de Madrid, España.

Foucault, M. (1994): "La ética del cuidado de sí como práctica de libertad", en Ditset écrits (1954-1988), t. N (1980-1988), Gallimard, París. Disponible en: En https://revistas.unc.edu.ar.

Foucault, M. (1999): Estética, Ética y Hermenéutica, Barcelona, Paidós.

Foucault, M. (2002): Vigilar y castigar. Nacimiento de la prisión, Buenos Aires, Siglo XXI Editores.

Fuentes, C. (1972): La nueva novela hispanoamericana, México, Joaquín Mortiz.

García Márquez, G. (1982): “La soledad en América Latina", Discurso de aceptación del premio Nobel, 12 de octubre de 1982. Disponible en Biblioteca virtual Miguel de Cervantes: https://cvc.cervantes.es/actcult/ garcia_marquez/audios/gm_nobel.htm\#: :text=Una\%20 nueva\%20y\%20arrasadora\%20utop\%C3\%ADa,segunda\%20oportunidad\%20sobre\%20la\%20tierra.

García Márquez, G. (2015): El otoño del patriarca, México, Diana.

Goloboff, G. (1991): "Roa y la consciencia histórica”, Cuadernos hispanoamericanos, 493-494, pp. 129-135.

González, P. (1980) Dictaduras y democracias en 
América Latina. En: Dictaduras y dictadores. Ed. por Labastida, J. México: Siglo XXI Editores, 222-239.

Habermas, J. (1989): "La soberanía popular como procedimiento”, Cuadernos políticos, 57, pp. 53-69.

Jouvenal, B. (2008): Sobre el poder: Historia natural de su crecimiento, Madrid, Unión editorial.

Labastida, J. (1980): Dictaduras y Dictadores, México, Siglo XXI Editores.

Lipovetsky, G. (1986): La era del vacío. Ensayos sobre el individualismo contemporáneo, Barcelona, Anagrama,

Lukes, S. (2007): El poder. Un enfoque radical, Madrid, Siglo XXI

Martínez, T., P. Pasolini, M. Bonasso, A. Gándara, N. Pernett, A. Pauls, G. Belli y M. García (2014): “García Márquez Gabriel 1927-2014. Dossier”, Disponible en: https://sinpermiso.info/sites/default/files/textos/ pasomarq.pdf

Mendoza, P. (2015): El olor de la guayaba. Conversaciones con Gabriel García Márquez, México, Diana.

Menton, S. (1981): "Ver para no creer: El otoño del Patriarca”, en P. Earle, ed, Gabriel García Márquez. El escritor y la crítica, Madrid, Taurus, pp. 189-209.

Milliani, D. (1981): "El dictador, objeto narrativo en El recurso del método", Revista Iberoamericana, 114, pp. 189-225.

Moreno, F. (2016): "La madre del dictador. Otra lectura para El otoño del Patriarca”, Meridional. Revista
Chilena de Estudios Latinoamericanos, 6, pp. 13-35.

Noguerol, F. (1992): “El dictador latinoamericano (aproximación a un arquetipo narrativo)", Philologia hispalensis, 7, pp. 91-102.

Ortega, J. (1978): "El otoño del Patriarca: Texto y cultura”, Hispanic Review, 46 (4), pp. 421-446.

Pacheco, C. (1987): Narrativa de la dictadura y la crítica literaria, Caracas, Celarg.

Parsons, T. (1963): “On the concept of political power", Proceedings of the American Philosophical Society, 107 (3), pp. 232-262.

Poulantzas, N. (2007): Poder político y clases sociales en el Estado capitalista, México, Siglo XXI Editores.

Rama, A. (1976): Los dictadores latinoamericanos, México, Fondo de Cultura Económica.

Rama, A. (1986): La Novelaen América Latina. Panoramas 1920-1980, Montevideo, Universidad Veracruzana.

Recasens, L. (1998): Tratado general de Sociología, México, Porrúa.

Rodríguez, R. (2015): Sin retorno. Variaciones sobre archivo y narrativa latinoamericana, Buenos Aires, La Cebra.

Rouquié, A. (1981): “Dictadores militares y legitimidad en América Latina”, Crítica y Utopía. Latinoamericana de Ciencias Sociales, 5, pp. 1-9.

Sandoval, A. (1989): Los dictadores y la dictadura en la 
novela Hispanoamericana: 1851-1978, México, UNAM.

Subercaseaux, B. (1980): “Tirano Banderas en la narrativa hispanoamericana (La novela

del dictador 1926, 1976)", Cuadernos Hispanoamericanos, 359, pp. 323-340.

Weber, M. (1964): Economía y sociedad. Esbozo de sociología comprensiva, México, FCE.

Weber, M. (1979): El político y el científico, Madrid, Alianza Editorial.

\section{Notas}

${ }^{1}$ Ante la complejidad del término y la diversidad de posturas teóricas se hallan en la literatura especializada propuestas de enfoques que persiguen ordenar el caos conceptual y permiten agruparlas de acuerdo con diversos criterios. Autores como Steven Lukes (2007) separa las concepciones del poder en tres; unidimensionales o pluralistas que conciben al poder como la prevalencia en la toma de decisiones donde haya conflictos observables, en ella se ubican autores como Polsby, Wolfinger y Dahl; bidimensionales cuya definición de poder se bifurca en dos. La primera, se refiere a las formas de control de A sobre By, la segunda la consecución de la obediencia mediante la amenaza, entre sus partidarios se encuentran Bachrach y Baratz y; enfoque tridimensional o tercera dimensión del poder sustentada por Lukes para quien el poder moldea percepciones, preferencias y cogniciones. Por otra parte, Byung-Chul Han (2017) pretende encontrar una concepción dinámica que permita unificar las divergencias en torno a él clarificando su concepción desde la lógica, la semántica, la metafísica, la política y la ética del poder.

${ }^{2}$ Autores como Jurguen Habermas encuentran la legitimación del poder a través del diálogo. El filósofo alemán relaciona al poder con el consenso, la comunicación, el acuerdo entre los ciudadanos y la exposición de argumentos, es decir, el poder político se encuentra legitimado solo cuando éste es generado comunicativamente. El poder legítimo surge sin coacciones (Habermas, 1989).

3 Talcott Parsons desde una óptica sistémica relaciona al poder con las metas colectivas y el consenso, pues define a este como "Una capacidad generalizada de garantizar el cumplimiento de obligaciones vinculantes por parte de unidades dentro de un sistema de organización colectiva, cuando las obligaciones se legitiman mediante la referencia a su repercusión en las notas colectivas y donde, en caso de actitudes recalcitrantes, se presuma la ejecución mediante sanciones situacionales negativas, cualquiera que sea el agente efectivo de tal ejecución" (Parsons, 1963: 237).

4Elcambio del modelo piramidal producela modificación en las relaciones burocráticas del poder o liquidación de las mecánicas del poder clásico (abolición de la separación dirigente-ejecutante, descentralización y diseminación) a la autogestión o creación de sujetos políticos autónomos a través de la circulación y tratamiento de las fuentes de información ejercidos como culto del yo en las sociedades del vacío (Lipovetsky, 1986: 25).

${ }^{5}$ Labastida (1980: 222-239). 